\title{
CONSTITUCIONALISMO E DEMOCRACIA: UMA ANÁLISE CRÍTICA DO PROCESSO ELETIVO DE MAGISTRADOS PARA TRIBUNAIS SUPERIORES DA BOLÍVIA
}

\author{
CONSTITUTIONALISM AND DEMOCRACY: A CRITICAL ANALYSIS OF THE \\ JUDICIAL ELECTIONS FOR BOLIVIA'S SUPERIOR COURTS
}

Thiago Burckhart ${ }^{1}$

\begin{abstract}
RESUMO
O constitucionalismo contemporâneo abriu caminho para a consolidação das "democracias constitucionais" em grande parte do globo. No entanto, embora os ideais do constitucionalismo e da democracia integraram-se sinergicamente, permanece subjacente a elas uma "tensão produtiva". Mais recentemente, em 2009, a Bolívia introduziu em seu texto constitucional a eleição de magistrados para tribunais superiores, sendo esta uma inovação sem precedentes na história do constitucionalismo moderno. Nesse sentido, este artigo objetiva analisar criticamente o processo eletivo de magistrados na Bolívia, focalizando as possíveis contribuições desta experiência para a tensão produtiva entre constitucionalismo e democracia. O trabalho conclui que as eleições aprofundam a experiência democrática e constitucional na Bolívia, mas aponta para a necessidade de aprimoramento normativo-institucional do processo eletivo. $O$ trabalho insere-se no campo da teoria da Constituição e da teoria política, em abordagem funcionalestruturalista, e divide-se em três partes: I - Constitucionalismo e democracia: categorias em "tensão"; II - O novo constitucionalismo boliviano: uma nova jurisdição constitucional; III - A experiência de eleição de magistrados para os tribunais superiores da Bolívia: uma análise crítica.
\end{abstract}

PALAVRAS-ChAVE: Constitucionalismo; Democracia; Bolívia; Eleições judiciais.

\begin{abstract}
Contemporary constitutionalism has paved the way for the consolidation of "constitutional democracies" in much of the globe. However, while the ideals of constitutionalism and democracy have been synergistically integrated, a

\footnotetext{
1 Mestre em Direito pela Universidade Federal de Santa Catarina, UFSC. Pesquisador do Centro Didattico Euroamericano Sulle Politiche Costituzionali (Cedeuam, Itália-Brasil). Pesquisador do Núcleo de Estudos em Constitucionalismo, Internacionalização e Cooperação (Constinter, Furb). Pesquisador colaborador da Academia Brasileira de Direito Constitucional, ABDConst. Membro da Réseau ALEC "Amérique Latine, Afrique, Europe et Caraïbe" sobre «Terrotoires, populations vulnérables et politiques publiques», vinculada à Université de Limoges, França. E-mail: thiago.burckhart@outlook.com
} 
BURCKHART, Thiago. Constitucionalismo e Democracia: uma análise crítica do processo eletivo de magistrados para tribunais superiores da Bolívia. Revista Eletrônica Direito e Política, Programa de Pós-Graduação Stricto Sensu em Ciência Jurídica da UNIVALI, Itajaí, v.14, n.2, ${ }^{\circ}$ quadrimestre de 2019. Disponível em: www.univali.br/direitoepolitica - ISSN 1980-7791

"productive tension" remains behind them. More recently, in 2009, Bolivia introduced in its constitutional text the election of magistrates to higher courts, an innovation unprecedented in the history of modern constitutionalism. In this sense, this article aims to critically analyze the elective process of magistrates in Bolivia, focusing on the possible contributions of this experience to the productive tension between constitutionalism and democracy. The paper concludes that the elections deepen the democratic and constitutional experience in Bolivia, but points to the need for institutional-normative improvement of the elective process. The work is part of the theory of the Constitution and political theory, in a functionalstructuralist approach, and is divided into three parts: I - Constitutionalism and democracy: categories in "tension"; II - The new Bolivian constitutionalism: a new constitutional jurisdiction; III - The experience of the election of magistrates to the superior courts of Bolivia: a critical analysis.

KEYWORDS: Constitutionalism; Democracy; Bolivia; Judicial elections.

\section{INTRODUÇÃO}

O processo de "globalização do constitucionalismo", posto em cena a partir do final da Segunda Guerra Mundial, deu sustentação para a configuração em nível teórico e empírico ao "constitucionalismo contemporâneo". Tal processo é marcado pela elaboração de novas constituições rígidas nas mais variadas partes do globo e, consequentemente, pelo aprimoramento da jurisdição constitucional a partir da criação de Tribunais Constitucionais com atribuição de realizar o controle de constitucionalidade. No entanto, sob o manto de uma das categorias corolárias deste processo, qual seja, "democracia constitucional", encobre-se uma tensão histórica entre os pressupostos democráticos e aqueles relativos ao constitucionalismo. A tensão entre estas categorias marca a histórica de evoluções aquisitivas do constitucionalismo moderno, de modo que a depender do desenho institucional de cada país ela pode tornar-se mais evidente ou, em outros casos, mais discreta.

Recentemente, os países da América Latina passaram por profundos processos de transformação constitucional. Desde a década de 1980, grande parte dos países promulgaram novos textos que inauguraram novos momentos políticos marcados pela superação de governos autoritários e ditatoriais. Mais recentemente, a Constituição da Bolívia, promulgada em 2009, foi resultado de um processo mais 
BURCKHART, Thiago. Constitucionalismo e Democracia: uma análise crítica do processo eletivo de magistrados para tribunais superiores da Bolívia. Revista Eletrônica Direito e Política, Programa de Pós-Graduação Stricto Sensu em Ciência Jurídica da UNIVALI, Itajaí, v.14, n.2, $2^{\circ}$ quadrimestre de 2019. Disponível em: www.univali.br/direitoepolitica - ISSN 1980-7791

amplo que ficou conhecido como "novo constitucionalismo latino-americano", caracterizado pela ampliação do rol de direitos, de sujeitos de direitos, pela virada biocêntrica na proteção dos direitos da natureza, pela refundação do Estado boliviano a partir da inserção de dois novos poderes - além daqueles tradicionais - e pela criação de novos Tribunais superiores, com a atribuição de dar a interpretação máxima sobre as disposições da referida Constituição.

Dentre as inovações da nova Constituição boliviana para o constitucionalismo latino-americano está a inserção de mecanismos eletivos para a escolha de membros dos referidos tribunais superiores, o que incrementa a concepção regional de democracia eletiva e participativa. Desde a promulgação da Constituição, os cidadãos bolivianos já se dirigiram duas vezes às urnas para a escolha de magistrados para a composição dos referidos tribunais. Tomando em consideração a discussão relativa à tensão histórica entre constitucionalismo e democracia, bem como a necessidade de conciliar ambos os ideais para uma prática democrática e constitucional emancipatória, este artigo busca responder ao seguinte questionamento: de que maneira o processo eletivo para magistrados de tribunais superiores da Bolívia impacta e contribui teórica e empiricamente para referida conciliação?

Nesse sentido, o presente artigo busca fornecer subsídios teóricos para refletir sobre a "tensão construtiva" existente entre constitucionalismo e a democracia na contemporaneidade, focalizando as possíveis contribuições da experiência boliviana, calcada nas inovações do "novo constitucionalismo latino-americano", para (re)conceber esta tensão produtiva. $O$ trabalho insere-se no campo da teoria da Constituição e da teoria política, com aportes da sociologia do direito, em abordagem estrutural-funcionalista, e divide-se em três capítulos: I Constitucionalismo e democracia: categorias em "tensão"; II - O novo constitucionalismo boliviano: uma nova jurisdição constitucional; III - A experiência de eleição de magistrados para os tribunais superiores da Bolívia: uma análise crítica. 
BURCKHART, Thiago. Constitucionalismo e Democracia: uma análise crítica do processo eletivo de magistrados para tribunais superiores da Bolívia. Revista Eletrônica Direito e Política, Programa de Pós-Graduação Stricto Sensu em Ciência Jurídica da UNIVALI, Itajaí, v.14, n.2, 20 quadrimestre de 2019. Disponível em: www.univali.br/direitoepolitica - ISSN 1980-7791

\section{CONSTITUCIONALISMO E DEMOCRACIA: CATEGORIAS EM "TENSÃO"}

A segunda metade do século $X X$ foi marcada pela ascensão do que o teórico Bruce Ackerman chamou de "constitucionalismo global"2. Trata-se do processo de internacionalização do direito constitucional e do ideal do constitucionalismo³ inclusive para regiões que historicamente não haviam aberto caminho para a experiência constitucional bem como para o constitucionalismo. 0 constitucionalismo, entendido como movimento político, social, cultural e jurídico que tem por objetivo a positivação de direitos fundamentais e a organização do Estado mediante a lógica de separação de poderes, deixou de ser um ideal em grande medida atinente às circunferências do território nacional e ocidental e passou a tornar-se um valor e um fenômeno tendencialmente universal ${ }^{4}$.

O "constitucionalismo contemporâneo" - categoria utilizada para referir-se às inovações constitucionais trazidas por diversas ordens constitucionais após o fim da Segunda Guerra Mundial - teve por corolárias as constituições da Alemanha e Itália, de modo que seus ideais foram, pelo menos em parte, difundidos para os demais movimentos constitucionais que foram postos em cena posteriormente, sobretudo na Europa e na América Latina. O constitucionalismo contemporâneo possui características e peculiaridades que distinguem-no do constitucionalismo moderno de matriz liberal e social, mas que não se desvencilham deles por completo. Por um lado é marcado pelo nascimento de novos direitos e novos sujeitos de direito ${ }^{5}$, sobretudo em países ocidentais, alicerçados no princípio da dignidade da pessoa humana como crítica ao positivismo exegético e normativista. Por outro, é fortemente marcado pelo aprimoramento da jurisdição constitucional

${ }^{2}$ ACKERMAN, Bruce. The Rise of World Constitutionalism. Virginia Law Review, 83, no. 4, pp. 771-797, 1997.

${ }^{3}$ Cfe. TUSHNET, Mark. The inevitable internationalization of constitutional law. Virginia Journal of International Law, vol. 49:4, 2009; CANOTILHO, José Joaquim Gomes. Os métodos do achamento político. In: CANOTILHO, José Joaquim Gomes et al. Comentários à Constituição do Brasil. São Paulo : Saraiva, 2013.

${ }^{4}$ Cfe. ONIDA, Valerio. La Costituzioni ieri e oggi. Bologna : Il Mulino, 2008.

5 Para Norberto Bobbio essa época ficou conhecida como "era dos direitos". BOBBIO, Norberto. A Era dos Direitos. Rio de Janeiro : Elsevier, 2004. 
BURCKHART, Thiago. Constitucionalismo e Democracia: uma análise crítica do processo eletivo de magistrados para tribunais superiores da Bolívia. Revista Eletrônica Direito e Política, Programa de Pós-Graduação Stricto Sensu em Ciência Jurídica da UNIVALI, Itajaí, v.14, n.2, 20 quadrimestre de 2019. Disponível em: www.univali.br/direitoepolitica - ISSN 1980-7791

por meio da criação de tribunais constitucionais para a realização do controle de constitucionalidade de leis e demais atos normativos.

Nesse sentido, o processo de constitucionalização do direito ${ }^{6}$, a partir dos ditames de novas Constituições marcadamente rígidas, abre espaço para que os tribunais constitucionais assumam o papel - questionado por alguns teóricos - de "guardião da Constituição"7 , na medida em que Ihes é atribuída a competência de interpretar em última instância o texto constitucional em diversos países e contextos, interferindo não poucas vezes na dinâmica dos processos políticos internos. Desde então, a jurisdição constitucional passa paulatinamente a assumir um papel de centralidade no que se refere à dinâmica político-constitucional nos mais diferentes países que adotaram este modelo - impulsionados pela "judicialização da política e da mega-política"8.

Ao mesmo passo em que o constitucionalismo se lança como ideal global, observase que a democracia também passa a ganhar espaço e legitimidade em nível universal como regime de governo mais aceitável, ideal e legítimo. Nas palavras de Gustavo Zagrebelsky, a partir "da segunda metade do século XX, a democracia é um conceito que se estabeleceu no léxico do homem político e constitui a categoria base em que se colocam e se confrontam todas as nossas ações, relações e pensamentos" ${ }^{\prime \prime}$. Após séculos de rejeição e tratamento pejorativo ao ideário democrático tanto no plano teórico quanto na prática política e institucional ${ }^{10}$, a democracia "vem ganhando legitimidade universal", ao passo que no campo da

6 Para aprofundamentos, ver: FAVOREU, Louis. La constitucionalización del derecho. Revista de Derecho, Volumen XIII, 2001.

7 O debate sobre "quem deve ser o guardião da Constituição" marcou presença em longo tempo na história da teoria e filosofia constitucional: KELSEN, Hans. Jurisdição Constitucional. São Paulo : Martins Fontes, 2003; SCHMITT, Carl. O guardião da Constituição. Belo Horizonte : Del Rey, 2007.

8 HIRSCHL, Ran. Towards Juristocracy: the origins and consequences of the new constitutionalism. Cambridge: Harvard University Press, 2007.

9 Tradução nossa: "Dalla seconda metà del secolo XX, la democrazia è parola che si è impadronita del lessico degli uomini politici e constituisce la categoria-base su cui si collocano e a cui si confrontano tutte nostre azioni, relazioni e pensieri". ZAGREBELSKY, Gustavo. Imparare democrazia. Torino :Einaudi, 2007, p. 3.

10 De acordo com David Held, "nos registros que temos pouco é dito sobre a democracia da Grécia até a Europa e América do Norte do século dezoito. A ampla adesão à democracia como forma adequada de organizar a vida política tem menos de cem anos de idade". HELD, David. Modelos de democracia. Belo Horizonte : Paideia, 1987, p. 1. 
BURCKHART, Thiago. Constitucionalismo e Democracia: uma análise crítica do processo eletivo de magistrados para tribunais superiores da Bolívia. Revista Eletrônica Direito e Política, Programa de Pós-Graduação Stricto Sensu em Ciência Jurídica da UNIVALI, Itajaí, v.14, n.2, 20 quadrimestre de 2019. Disponível em: www.univali.br/direitoepolitica - ISSN 1980-7791

teoria política o que se evidencia é que "a teoria da democracia se tornou a preocupação dominante"1112.

A democracia deixa de ser concebida de forma pejorativa para tornar-se o regime de governo dominante no Ocidente e em grande parte do Oriente - pelo menos do ponto de vista formal. Desde os Estados Unidos até Japão, da Índia à África do Sul, da Bolívia à Nova Zelândia, a democracia se converteu numa espécie de aspiração global. Muito embora o modelo de democracia predominante atualmente tenha sofrido uma série de transformações a partir do século XVIII - tendo em vista, sobretudo, o atrelamento do ideário democrático à noção de "representação", mostrando-se evidente um afastamento da democracia de sua semântica inicial, relacionada com o "governo do povo"13, além do nascimento das teorias elitistas da democracia ${ }^{14}$, que procuraram preencher seu significado a partir da referência e atrelamento ao ideal aristocrático, - é evidente que a democracia é e se coloca hodiernamente como uma forma de governo e aspiração política em grande parte do mundo.

Nesse contexto, à medida em que a democracia se tornou um objeto de tutela das Constituições - o que deu sustentação à criação do conceito de "Estado de Direito", num primeiro momento, e mais recentemente, ao conceito de "Estado democrático de direito" - , a literatura jurídica passou a adotar a expressão "democracia constitucional" como consenso inequívoco, indubitável e descritivo de uma nova realidade constitucional emergente. Referido termo é utilizado para diagnosticar e descrever os países que passaram a adotar a democracia como regime político e, ao mesmo tempo, Constituições no sentido moderno. Este termo, entretanto, encoberta uma tensão que marcou a trajetória do constitucionalismo a longo da modernidade: trata-se da tensão entre constitucionalismo vs. democracia.

\footnotetext{
11 MIGUEL, Luis Felipe. Democracia e representação: territórios em disputa. São Paulo: Editora Unesp, 2014, p. 11-12.

12 Nesse mesmo sentido, também ver: SARTOTI, Giovani. A teoria da democracia revisitada: o debate Contemporâneo. São Paulo, Editora Ática, 1984; ZOLO, Danilo. Prefazione. In: ZOLO, Danilo. La cittadinanza: appartenenza, identità, diritti. Roma : Laterza, 1994.

13 Faz-se aqui referência aos gregos e à obra de Aristóteles.

14 Diversos autores poderiam ser nomeados nessa corrente de pensamento, de modo que mais preminente talvez seja: SCHUMPETER, Joseph. Capitalismo, socialismo e democracia. Rio de Janeiro: Fundo de Cultura, 1961.
} 
BURCKHART, Thiago. Constitucionalismo e Democracia: uma análise crítica do processo eletivo de magistrados para tribunais superiores da Bolívia. Revista Eletrônica Direito e Política, Programa de Pós-Graduação Stricto Sensu em Ciência Jurídica da UNIVALI, Itajaí, v.14, n.2, 20 quadrimestre de 2019. Disponível em: www.univali.br/direitoepolitica - ISSN 1980-7791

De acordo com Roberto Gargarella, o conflito entre ambos ideais surge do feito de que eles apelam a princípios diferentes. Os compromissos democráticos apelam, em primeira vista, a não reconhecer limites políticos, de acordo com o qual não há nenhuma autoridade superior que aquela do "povo" atuando coletivamente. Por outro lado, os ideais relativos à Constituição os aos direitos humanos levam a pensar justamente em limites formais e materiais, capazes de resistir à pressão de qualquer grupo e, sobretudo, aos grupos politicamente majoritários de uma sociedade ${ }^{15}$. Este embate, de acordo com Gargarella, ocorre em uma espécie de tensão na medida em que, de um lado, o povo almeja e necessita do direito na medida em que é imperativo estar sujeito à regras impessoais que se edificam ante a vontade discricionária de algum personagem político todo-poderoso. No entanto, e por outro lado, em alguns momentos o "povo" também encontra-se preso dentro das formalidades do mesmo direito, impedido de transcender politicamente às normas ${ }^{16}$.

Do ponto de vista teórico, constitucionalismo e democracia representam valores políticos diferentes e, em certo sentido, divergentes. O constitucionalismo é aliado ao liberalismo moderno que, de acordo com Norberto Bobbio ${ }^{17}$, é um ideal que por muito tempo se contrapôs à democracia. Muito embora Bobbio entenda que estes ideais tenham sido, ao longo da modernidade e sobretudo a partir da segunda metade do século $X X$, se aproximado e cada vez mais produzido sinergias e complementaridades, também é fato que uma tensão histórica ainda marca de modo mais ou menos acentuado - a depender do contexto - as "democracias constitucionais" da contemporaneidade. Em efeito, o processo de constitucionalização da política e, consequentemente, da democracia, e o processo de democratização do constitucionalismo que foram postos em cena no âmbito do constitucionalismo contemporâneo através de mecanismos de participação direta, ainda encontra uma série de dificuldades e desafios no âmbito da práxis constitucional hodierna.

\footnotetext{
15 BOBBIO, Norberto. Liberalismo e democracia. São Paulo : Brasiliense, 2006.

16 GARGARELLA, Roberto. Constitucionalismo vs. democracia. In: FABRA ZAMORA, Jorge Luíz; SPECTOR, Ezequiel. Enciclopedia de filosofia y teoría del derecho. Vol.III. Ciudad de México : Universidad Nacional Autonoma de México, 2015.

17 Cfe. BOBBIO, Norberto. Liberalismo e democracia. São Paulo : Brasiliense, 2006.
} 
BURCKHART, Thiago. Constitucionalismo e Democracia: uma análise crítica do processo eletivo de magistrados para tribunais superiores da Bolívia. Revista Eletrônica Direito e Política, Programa de Pós-Graduação Stricto Sensu em Ciência Jurídica da UNIVALI, Itajaí, v.14, n.2, 20 quadrimestre de 2019. Disponível em: www.univali.br/direitoepolitica - ISSN 1980-7791

Essa discussão remonta os debates levantados pelo constitucionalista estadunidense Stephen Holmes em seus estudos sobre os precompromissos e o paradoxo da democracia ${ }^{18}$. O autor enfrenta os questionamentos que estão na centralidade da teoria da Constituição e da democracia, como o porquê de uma geração ter de obrigar juridicamente outra e como assegurar as condições de um debate público, buscando compreender se os compromissos constitucionalmente inscritos são ou não antidemocráticos, já que rejeitam a possibilidade de deliberação pública de determinadas matérias pelas futuras gerações. Para o autor, existe uma racionalidade por trás da noção de pré-compromisso, na medida em que a Constituição seria um instrumento jurídico e político para a garantia da própria democracia, isso porque os limites ao poder nem sempre assumem uma dimensão negativa, pois uma Constituição não apenas impede maiorias, ela também atribui poderes, sendo este o paradoxo, e não a contradição, inerente aos pré-compromissos constitucionais.

Cabe fazer referência à perspectiva de Cass Sunstein ${ }^{19}$, que ao buscar a conciliação entre os princípios da democracia e do constitucionalismo, infere que a tensão entre estes termos é maior ou menor a depender dos arranjos da maquinaria constitucional presentes em cada Constituição. Nesse sentido, ao estabelecer os desenhos do aparato constitucional bem como os direitos fundamentais, as Constituições também estabelecem o desenho da democracia podendo atribuir maior ou menor espaço para a liberdade dos cidadãos ${ }^{20}$. Neste contexto, é na dinâmica das relações entre os poderes, do efetivo desenho constitucional destes poderes - suas atribuições e competências - e no grau de respeito aos direitos fundamentais que é possível se conceber a relação - e a tensão - entre o constitucionalismo e a democracia hodiernamente.

Neste mesmo sentido, Jürgen Habermas, ao construir sua teoria do direito e da democracia, aponta para a necessidade de produzir uma confluência harmônica

\footnotetext{
18 HOLMES, Stephen. El precompromiso y la paradoja de la democracia. In : ESLTER, Jon; SLAGSTAD, Rune. Constitucionalismo y democracia. México : Fondo de Cultura Económica, 1999, pp. 217-262.

${ }^{19}$ Cfe. SUNSTEIN, Cass. Introducción. In: ESLTER, Jon; SLAGSTAD, Rune. Constitucionalismo y democracia. México : Fondo de Cultura Económica, 1999.

20 SUNSTEIN, Cass. Designing democracy: what constitutions do. Cambridge : Oxford University Press, 2001.
} 
BURCKHART, Thiago. Constitucionalismo e Democracia: uma análise crítica do processo eletivo de magistrados para tribunais superiores da Bolívia. Revista Eletrônica Direito e Política, Programa de Pós-Graduação Stricto Sensu em Ciência Jurídica da UNIVALI, Itajaí, v.14, n.2, ${ }^{\circ}$ quadrimestre de 2019. Disponível em: www.univali.br/direitoepolitica - ISSN 1980-7791

entre a autonomia privada e a autonomia pública, processos que conviveram em tensão ao longo da modernidade. As noções de autonomia privada e autonomia pública estão ligadas aos ideiais modernos de liberdade, no primeiro caso, e de igualdade, no segundo, que se manifesta ainda na dicotomia entre direitos humanos, que no primeiro caso é entendido como expressão da autodeterminação moral, e a soberania popular, que no segundo refere-se à autorealização ética ${ }^{21}$. A teoria habermasiana do direto - que se edifica a partir de uma perspectiva procedimental do direito e da democracia - busca coligar ambas as perspectivas entendendo que elas pressupõem-se reciprocamente ${ }^{22}$, conferindo uma à outra legitimidade para ambos os processos.

Tomando isso em consideração, entende-se neste trabalho que constitucionalismo e democracia são valores teórica e empiricamente conciliáveis. No entanto, na base desta conciliação remanesce uma tensão que deve ser encarada como "produtiva"23. Ela se dimensiona a partir da arquitetura institucional prevista no próprio texto constitucional e tem na atribuição da jurisdição constitucional o lócus por excelência no qual esta discussão se desenvolve com maior afinco. Isso porque a atuação dos magistrados constitucionais é questionada por inúmeros teóricos quanto à sua legitimidade de restringir, mediante o controle de constitucionalidade de leis - que utiliza a Constituição como base precípua, um documento simultaneamente político e jurídico - a política ordinária. Nesse contexto, a proposta de conciliação entre constitucionalismo e democracia inexoravelmente

${ }^{21}$ HABERMAS, Jürgen. Direito e democracia: entre facticidade e validade. Vol. II. Tradução de Flávio Siebeneichler. Rio de Janeiro : Tempo brasileiro, 1997, p. 183.

22 "Desse modo, a autonomia privada e a autonomia pública se pressupõe recípricamente. A conexão interna entre democracia e estado de direito consiste assim que, de um lado os cidadãos somente podem fazer uso adequado de uma autonomia pública se eles são suficientemente independentes com base numa autonomia privada assegurada em igual medida, que eles também sópodem gozar de autonomia privada na mesma medida se eles como cidadãos fazem um uso adequado de sua autonomia política. Por isso, direitos fundamentais liberais e políticos são indivisíveis. A imagenm denúcleo e casca é errática - como se houvesse um âmbito nuclear de direitos elementares de liberdade que pudessem pretender primazia diante dos direitos de comunicação e participação.Para o tipo ocidental de legitimação, a cooriginariedade dos direitos de liberdade e cidadania é essencial". HABERMAS, Jüergen. A constelação pós-nacional: ensaios políticos. São Paulo : Littera Mundi, 2001, p.176-177.

23 Cfe. CHUEIRI, Vera Karam de. Constituição radical: uma ideia e uma prática. Revista da Faculdade de Direito da UFPR, Curitiba, n. 58, 2013. 
BURCKHART, Thiago. Constitucionalismo e Democracia: uma análise crítica do processo eletivo de magistrados para tribunais superiores da Bolívia. Revista Eletrônica Direito e Política, Programa de Pós-Graduação Stricto Sensu em Ciência Jurídica da UNIVALI, Itajaí, v.14, n.2, 20 quadrimestre de 2019. Disponível em: www.univali.br/direitoepolitica - ISSN 1980-7791

perpassa pela discussão atinente à jurisdição constitucional, bem como pela atuação dos tribunais constitucionais nas democracias constitucionais ${ }^{24}$.

\section{O NOVO CONSTITUCIONALISMO BOLIVIANO: UMA NOVA JURISDIÇÃO CONSTITUCIONAL}

Partindo de uma perspectiva holística, pode-se afirmar que as inovações constitucionais postas em cena na América Latina desde os anos 1980 se projetam na forma de um "novo constitucionalismo", que imprimem características peculiares e inovadoras. No entanto, a categoria "novo constitucionalismo latinoamericano" é utilizada neste artigo, e por grande parte da literatura jurídica, para referir-se às mais recentes evoluções aquisitivas que se deram nas Constituições do Equador (2008) e da Bolívia (2009), em razão destas terem sido responsáveis por inovações e contribuições profundas ao constitucionalismo moderno e para o "patrimônio comum do constitucionalismo democrático"25. Pode-se afirmar que este constitucionalismo é considerado "novo" por pelo menos três aspectos fundamentais: 1) pela virada biocêntrica no que se refere ao meio ambiente que permeia a relação dos cidadãos enquanto parte indissociável deste meio ${ }^{26}$; 2) pela inclusão das epistemologias do sul, que confluem para o reconhecimento indiscreto dos direitos indígenas de modo amplo ao longo do texto constitucional ${ }^{27}$; e, 3) pelo processo de refundação do Estado, calcado numa perspectiva essencialmente democrática, incluindo reformas que garantem participação popular e representatividade de minorias em instâncias até então não democratizadas. Neste trabalho, focaliza-se este terceiro aspecto.

\footnotetext{
24 Nesse sentido, a proposta deste artigo se afasta de outras que negam a tensão (Ronald Dworkin, Bruce Ackerman) e dos que dissolvem a tensão por negarem o controle judicial de leis (John Waldron e Mark Tushnet).

25 Cfe. ONIDA, Valerio. La Costituzioni ieri e oggi. Bologna : Il Mulino, 2008.

26 Para aprofundamentos, ver: MELO, Milena Petters. O patrimônio comum do constitucionalismo contemporâneo e a virada biocêntrica do "novo" constitucionalismo latinoamericano. Novos Estudos Jurídicos, v. 18, p. 74-84, 2013.

27 Para aprofundamentos, ver: SANTOS, Boaventura de Sousa; MENESES, Maria Paula. (Orgs.) Epistemologias do Sul. São. Paulo; Editora Cortez. 2010.
} 
BURCKHART, Thiago. Constitucionalismo e Democracia: uma análise crítica do processo eletivo de magistrados para tribunais superiores da Bolívia. Revista Eletrônica Direito e Política, Programa de Pós-Graduação Stricto Sensu em Ciência Jurídica da UNIVALI, Itajaí, v.14, n.2, 20 quadrimestre de 2019. Disponível em: www.univali.br/direitoepolitica - ISSN 1980-7791

O grau de novidade desta nova Constituição impulsionou o jurista Bartolomé Clavero a afirmar que, embora a Bolívia já tenha tido 15 Constituições ao longo de sua história republicana - sendo esta a 16a Carta -, "puede perfectamente decirse que, entre 1826 y 2009, Bolívia solo ha tenido en efecto una única constitución"28. Em efeito, a história constitucional boliviana não havia contado com profundas transformações Constitucionais como as evidenciadas com o texto de 2009. Nesse mesmo sentido, ainda cabe ressaltar, como aponta Roberto Gargarella, que as mudanças do ponto de vista institucional foram ainda mais limitadas, de modo que a tradição constitucional latino-americana conta, na maior parte das experiências constitucionais, com um aperfeiçoamento quase contínuo no que se refere ao reconhecimento de direitos fundamentais, mas com a permanência de estruturas autoritárias de Estado, da maquinaria estatal ${ }^{29}$.

Cabe mencionar que existem pelo menos dois fatores políticos que deram sustentação para as transformações constitucionais de 2009 na Bolívia. O primeiro diz respeito às transformações político-institucionais pregressas, sobretudo a partir dos anos 1990, que produziram, através da descentralização administrativoeleitoral e do reconhecimento cada vez maior dos direitos indígenas, como resultado das políticas de identidade e da diferença, a possibilidade de ascensão política dos partidos progressistas; e a firmação, no ano de 2004, do Pacto de Unidad Indígena, Originario y Campesino, que, por meio da coalizão política entre os movimentos indígenas e campesinos de variados espectros e origens geográficas, garantiu o apoio necessário para a vitória do MAS $^{30}$ nas eleições

28 CLAVERO, Bartolomé. Bolívia entre Constitucionalismo Colonial y Constitucionalismo Emancipatorio. Conferencia presentada em La Vicepresidencia de La Republica, 2009, p. 2.

29 GARGARELLA, Roberto. La sala de máquinas de la Constitución: dos siglos de constitucionalismo en América Latina (1810-2010). Buenos Aires : Katz Editores, 2014. Nesse mesmo sentido, para uma perspectiva crítica sobre a refundação do Estado na América Latina, ver: ACUNHA, Fernando José Gonçalves. Constitucionalismo, autoritarismo e democracia na América Latina: as recentes Constituições da Bolívia e do Equador e a persistência das tradições do constitucionalismo latino-americano. Tese de Doutoramento em Direito. Universidade de Brasília, 2017.

30 Movimento Político intitulado "Movimiento al Socialismo" liderado pelo atual presidente da Bolívia. 
BURCKHART, Thiago. Constitucionalismo e Democracia: uma análise crítica do processo eletivo de magistrados para tribunais superiores da Bolívia. Revista Eletrônica Direito e Política, Programa de Pós-Graduação Stricto Sensu em Ciência Jurídica da UNIVALI, Itajaí, v.14, n.2, 20 quadrimestre de 2019. Disponível em: www.univali.br/direitoepolitica - ISSN 1980-7791

maioritárias de 2005, dando sustentação e legitimidade ao processo de construção da nova Constituição do país ${ }^{31}$.

Nesse contexto, a novidade da "refundação do Estado" boliviano se plasma também em uma nova forma de compreender e "experienciar" o Estado. Trata-se da superação da noção tradicional de que o Estado é um ente superior, abstrato e sem conexão com a realidade, passando-se a difundir a concepção de que ele é formado por todos os seus cidadãos, ou seja, que o povo é o Estado, oferendo uma resposta pontual para o histórico "problema da correspondência"32. Esta é uma experiência inovadora sobretudo em razão do contexto político contemporâneo que redesenha e reconcebe a "forma Estado" a partir da lógica da "forma mercado"33, pela dominação econômica e financeira de multinacionais e do rentismo financeiro, fazendo referência a uma nova espécie de "lex marcatoria"34. Esta refundação, noutro sentido, assenta-se nas bases de uma perspectiva democrática ${ }^{35}$.

A história político-constitucional boliviana é, em efeito, marcada por uma série de contradições em razão das dificuldades em manter a estabilidade política e jurídica. Esta característica se deve, em grande medida, às alianças e conflitos existente entre as elites políticas e econômicas com o intuito de manutenção de seus interesses políticos e econômicos, ao passo que somente foi possível a subversão desta ordem com a ascensão de governos progressistas no século $X X I^{36}$. Nesse contexto, a refundação do Estado boliviano impactou para além de sua forma jurídica, também a sua "forma judicial". Historicamente, no que se refere à jurisdição constitucional e, especialmente, ao controle de constitucionalidade,

31 Cfe. DUVAL, Fábio Amaro da Silveira. Da polifonia à seletividade no discurso indigenista da esquerda boliviana. In: DUARTE, Rita. (Org.). Janus 2014. Conjuntura internacional - O estado do Estado - Metamorfoses da violência (1914-2014). 1ed.Lisboa: OBSERVARE - Universidade Autónoma de Lisboa, 2014, p. 78.

32 Cfe. TAPIA, Luis. Una reflexión sobre la idea de Estado plurinacional. Revista OSAL (Buenos Aires: CLACSO) Año VIII, No 22, 2007.

33 AMIRANTE, Carlo. Dalla forma stato alla forma mercato. Torino: Giappichelli, 2008.

34 SANTOS, Boaventura de Sousa. La globalización del derecho: los nuevos caminos de la regulación y la emancipación. Traducción de César Rodríguez. Bogotá : Instituto Latinoamericano de Servicios Legales Alternativos, ILSA, 1998.

35 SANTOS, Boaventura de Sousa. Refundación del Estado en América Latina: perspectivas desde una epistemología del Sul. Lima : Red Latinoamericana de Antropología Jurídica, 2010.

36 Trata-se do movimento político que levou à Presidência o primeiro indígena do país, Evo Morales. 
BURCKHART, Thiago. Constitucionalismo e Democracia: uma análise crítica do processo eletivo de magistrados para tribunais superiores da Bolívia. Revista Eletrônica Direito e Política, Programa de Pós-Graduação Stricto Sensu em Ciência Jurídica da UNIVALI, Itajaí, v.14, n.2, 20 quadrimestre de 2019. Disponível em: www.univali.br/direitoepolitica - ISSN 1980-7791

Norbert Lösing aponta que este instrumento conviveu com "un marco de condiciones difíciles"37 que, entretanto, marca a justiça constitucional e o Judiciário em grande parte dos países latino-americanos ${ }^{38}$.

Assim como outros países da América Latina, o constitucionalismo boliviano foi diretamente influenciado em sua gênese pela teoria do "judicial review" estadunidense. Em razão disso, criou-se um sistema "misto", como também é evidente em muitos países latino-americanos. Desde a primeira Constituição boliviana, promulgada em 1826 e conhecida como "Constitución bolivariana" - em razão da influência de Simón Bolívar em sua elaboração - previu-se uma espécie de justiça constitucional realizada por órgãos especiais ${ }^{39}$. No entanto, a consolidação do controle de constitucionalidade na via "concreta" somente foi possível com a também consolidação da "Suprema Corte de Justicia", que ocorrera a partir de $1851^{40}$. Foi entre 1861 e 1938 que este instrumento se consolidou na prática constitucional boliviana na figura da Suprema Corte, que se desprendeu deste mesmo órgão pela própria via jurisprudencial para permitir que os juízes ordinários também pudessem se recusar a aplicar normas que considerassem inconstitucionais.

O ponto de inflexão para a introjeção do sistema concentrado deu-se através da influência espanhola e foi resultado da Constituição de 1994. Como aponta Norbert Lösing, "Bolívia inició en 1993 y 1994 una reforma fundamental del Estado, cuyo pilar fundamental lo constituye la reforma de la justicia"41. A partir daí introduziuse a possibilidade também do controle de constitucionalidade concentrado no qual as decisões da Corte tem efeito erga omnes. Entretanto, pode-se afirmar que as reformas introduzidas pela Constituição de 2009 foram ainda mais profundas, pelo menos por dois motivos inovadores. O primeiro deles diz respeito ao incremento

37 LÖSING, Norbert. La jurisdiccionalidad constitucional en Latinoamerica. Traducción de Marcela Anzola Gil. Madrid : Dykinson, 2002

38 VARGAS LIMA, A. E. La evolución de la justicia constitucional en Bolivia. Apuntes sobre el modelo de control concentrado y plural de constitucionalidad. Anuario Iberoamericano de Justicia Constitucional, n. 20, 2016.

39 LÖSING, Norbert. La jurisdiccionalidad constitucional en Latinoamerica, p. 237.

40 Trata-se da consolidação de "um control concreto denormas en el marco de un proceso civil, com efectos inter partes". LÖSING, Norbert. La jurisdiccionalidad constitucional en Latinoamerica, p. 241.

${ }^{41}$ LÖSING, Norbert. La jurisdiccionalidad constitucional en Latinoamerica, p. 255. 
BURCKHART, Thiago. Constitucionalismo e Democracia: uma análise crítica do processo eletivo de magistrados para tribunais superiores da Bolívia. Revista Eletrônica Direito e Política, Programa de Pós-Graduação Stricto Sensu em Ciência Jurídica da UNIVALI, Itajaí, v.14, n.2, 20 quadrimestre de 2019. Disponível em: www.univali.br/direitoepolitica - ISSN 1980-7791

da jurisdição constitucional, que é em grande medida realizada pelo Tribunal Constitucional Plurinacional (art.196), mas também pelo Tribunal Supremo de Justicia (art. 181) e pelo Tribunal Agroambiental (art. 186), que juntamente com o Consejo de Justicia (art. 193), formam a cúpula do Judiciário boliviano ${ }^{42}$ O segundo - objeto desta pesquisa - diz respeito ao processo eletivo de juízes para os tribunais superiores - todos os quatro órgão citados acima. Trata-se de uma experiência única no constitucionalismo moderno, pois embora existam experiências de eleição de juízes ordinários - sobretudo em países da common law - esta é a primeira vez que se tem registro de eleições diretas para magistrados de tribunais superiores.

A nova constituição detalha cada uma das atribuições e o modo de eleição dos membros de cada tribunal superior. Como disposições gerais dos órgãos judiciais, aponta em seu artigo 178 que o Judiciário boliviano deve se sustentar nos princípios da independência, imparcialidade, segurança jurídica, publicidade, probidade, celeridade, harmonia social e respeito aos direitos. Tomando isso em consideração, o texto constitucional detalha num primeiro momento o "Tribunal Supremo de Justicia" nos artigos 181 a 185. Nestes dispositivos, a Constituição determina que este é o órgão máximo da jurisdição ordinária, de modo que seus magistrados e magistradas devem ser eleitos mediante sufrágio universal (art. 182, I), em eleição definida por maioria simples dos votos (art. 182, V). A préseleção de membros para a eleição é realizada pela Asambleia Legislativa Plurinacional, remetendo os respectivos nomes para o órgão eleitoral responsável (art. 182, III). Para efetivamente concorrer ao cargo, o candidato deve cumprir com os requisitos dispostos no art. 182, VI, que são os que seguem: ter cumprido trinta anos de idade; possuir o título de advogado; ter desempenhado com honestidade y ética funções judiciais, profissão de advogado ou cátedra universitária durante oito anos; e não possuir qualquer sanção de destituição do Consejo de la Magistratura. A Constituição ainda estabelece a impossibilidade de

\footnotetext{
42 Ainda cabe ressaltar a abertura da Constituição para a "jurisdição indígena", reconhecida nos artigos 190-192 da Constituição. O artigo 190 inscreve que "Las naciones y pueblos indígena originario campesinos ejercerán sus funciones jurisdiccionales y de competencia a través de sus autoridades, y aplicarán sus principios, valores culturales, normas y procedimientos propios".
} 
BURCKHART, Thiago. Constitucionalismo e Democracia: uma análise crítica do processo eletivo de magistrados para tribunais superiores da Bolívia. Revista Eletrônica Direito e Política, Programa de Pós-Graduação Stricto Sensu em Ciência Jurídica da UNIVALI, Itajaí, v.14, n.2, $2^{\circ}$ quadrimestre de 2019. Disponível em: www.univali.br/direitoepolitica - ISSN 1980-7791

reeleição, fixa o período do mandato em seis anos (art. 183, I) e proíbe a realização de "campanhas eleitorais" nestes tipos de eleição ${ }^{43}$.

No que tange à jurisdição agroambiental, aplicam-se as mesmas regras estabelecidas para o Tribunal Supremo de Justicia. A diferença se refere ao tema de trabalho do órgão, motivo pelo qual se exige do candidato oito anos de experiência com atividades judiciais, na advocacia ou na docência em matéria de direito agroambiental (art. 187). Para o Consejo de la Magistratura - que é a instância responsável do regime disciplinar da jurisdição ordinária, agroambiental e das jurisdições especializadas, responsável também pelo controle e fiscalização do manejo administrativo e financeiro e da formulação de políticas para sua gestão - também segue as mesmas normas estipuladas ao Tribunal Supremo de Justicia. A diferença, presente no artigo 194, inciso I, refere-se aos requisitos do candidato, que deve possuir conhecimentos técnicos na área das atribuições relativas ao cargo.

Por fim, o Tribunal Constitucional Plurinacional, órgão responsável por velar pela supremacia da Constituição, exercer o controle de constitucionalidade e cautelar pelo respeito e vigência dos direitos e garantias fundamentais (art. 196, I). Para a eleição de seus membros também se adotam os mesmos critérios do Tribunal Supremo de Justicia, com algumas especificidades, como a exigência de experiência profissional com temáticas relativas ao direito constitucional, administrativo e direitos humanos por oito anos. Além disso, a Constituição também prevê que o Tribunal Constitucional Plurinacional deverá contar em sua composição com magistradas e magistrados eleitos com critérios de plurinacionalidade, com representação do sistema judicial ordinário e do sistema indígena originário campesino (artigo 197, I).

Pontua-se, como visto, que as coordenação das eleições dos magistrados fica a encargo do Órgano Electoral Plurinacional, conforme determina o artigo 208, inciso I da Constituição. Este órgão, que possui jurisdição em todo o território boliviano, é responsável pela realização dos processos eleitorais no país que estão

\footnotetext{
43 A proibição aos candidatos de realizarem campanha tem por objetivo evitar a influência de entidades privadas, sobretudo empresas, na eleição.
} 
BURCKHART, Thiago. Constitucionalismo e Democracia: uma análise crítica do processo eletivo de magistrados para tribunais superiores da Bolívia. Revista Eletrônica Direito e Política, Programa de Pós-Graduação Stricto Sensu em Ciência Jurídica da UNIVALI, Itajaí, v.14, n.2, $2^{\circ}$ quadrimestre de 2019. Disponível em: www.univali.br/direitoepolitica - ISSN 1980-7791

submetidas às disposições da Constituição, em especial àquelas que tratam da representação política (artigos 209 a 212), sendo também obrigação deste órgão garantir o sufrágio efetivo para o exercício de direitos políticos, individuais e coletivos; salvaguardar o exercício da democracia intercultural em todo o território do Estado Plurinacional; verificar em todas as fases dos processos eleitorais o estrito cumprimento do princípio da equivalência, paridade e alternância entre homens e mulheres na apresentação de candidaturas de âmbito nacional; e resolver com eficiência, eficácia, prontidão e probidade todos os procedimentos administrativos, técnico-eleitorais e contenciosos-eleitorais de seus conhecimentos (artigo 208, II).

Até o presente momento, foram realizados dois processos eletivos para magistrados dos tribunais superiores da Bolívia, uma em 2011 e outra em 2017, sendo que a próxima deverá ocorrer em 2023. Observa-se que, pelo menos do ponto de vista teórico e normativo, o processo eletivo para magistrados dos tribunais superiores representa um aprofundamentos da experiência democrática, na medida em que possibilita uma maior participação cidadã nas instâncias de poder judicial. Falta analisar, entretanto, as implicações desta prática no âmbito da sua práxis política e os problemas teóricos que esse processo acarreta.

\section{A experiência de eleição de magistrados para os tribunais superiores da Bolívia: uma análise crítica}

O processo eleitoral para magistrados na Bolívia fundamenta-se, do ponto de vista de sua práxis, em dos aspectos fundamentais. O primeiro deles diz respeito à histórica dificuldade de concretizar a independência judicial num país marcado pela instabilidade política e jurídica. O segundo está relacionado com o alargamento de uma dimensão de representação descritiva - indenitária -, nos moldes como bem define Hannah Pitkin, no âmbito da institucionalidade deste poder, que impactou diretamente a composição dos tribunais superiores. Ambos aspectos confluíram para dar sustentação às inovações normativas presentes na Constituição de 2009.Como aponta Jorge Lazarte Rojas, desde a fundação da república boliviana em 1825: 
BURCKHART, Thiago. Constitucionalismo e Democracia: uma análise crítica do processo eletivo de magistrados para tribunais superiores da Bolívia. Revista Eletrônica Direito e Política, Programa de Pós-Graduação Stricto Sensu em Ciência Jurídica da UNIVALI, Itajaí, v.14, n.2, ${ }^{\circ}$ quadrimestre de 2019. Disponível em: www.univali.br/direitoepolitica - ISSN 1980-7791

"[...] el sistema judicial nunca pudo asegurar el cumplimiento de su función, que es de hacer 'justicia', y que, portanto, la 'justicia' misma fracasó, con notables excepciones, dando lugar a que actuaran otras 'justicias' informales, de acción directa, venales o vendettas"44.

Em efeito, na Bolívia - como em grande parte dos países latino-americanos - a nomeação de juízes para as altas instâncias do Judiciário tem sido historicamente uma atribuição do poder político institucionalizado, no qual se encontra a ligação entre os que detém o poder e aqueles que devem decidir sobre a liberdade e o patrimônio dos cidadãos ${ }^{45}$. Num contexto marcado por um Estado deficiente, no qual historicamente se manifesta a ineficiência, corrupção e ingerência política ${ }^{46}$, a administração da justiça aparece casualmente vinculada à dependência do $\operatorname{poder}^{47}$.

Neste contexto, ganha relevância a proposta de repensar o modelo de garantia da independência judicial - garantia prevista na Constituição boliviana, assim como no Pacto Internacional de Direitos Civis e Políticos e na Convenção Americana de Direitos Humanos, que estabelecem o direito de todas as pessoas a serem assistidas por um juiz independente quando houver violação a um de seus direitos. Dessa forma, tomando em consideração que o processo de nomeação e escolha para magistrados das altas cortes do país é uma peça-chave para garantir a independência judicial, buscou-se, através da inserção do mecanismo de eleição direta popular de magistrados, uma forma de garantir a prevalência do referido princípio de direito.

Ocorre que tanto a eleição para magistrados na Bolívia possui duas fases. A primeira delas, conhecida como "pré-eleição", é realizada pelo Órgano Electoral Plurinacional, que é responsável pela verificação e indicação de procedência dos

\footnotetext{
44 ROJAS, Jorge Lazarte. La caja de Pandora de la justicia: el experimento del voto universal para elegir magistrados. Santa Cruz de la Sierra : Fundación Nueva Democracia, 2017, p. 29. Nesse mesmo sentido o autor afirma: "La ausencia de independencia de la justicia y los jueces, y su inefectividad, han sido los talones de Aquiles de la historia judicial de Bolívia", p.29.

45 PÁSARA, Luis. Elecciones judiciales en Bolívia: una experiencia inédita. Washington, DC : Due Process of Law Foundation, 2014.

46 QUIROGA, T. J. A. El colapso del sistema judicial, síntomas de la crisis del Estado corporativo. Nueva Cronica y Buen Gobierno, 16 abr 2014.

47 PÁSARA, Luis. Elecciones judiciales en Bolívia, p. 5.
} 
BURCKHART, Thiago. Constitucionalismo e Democracia: uma análise crítica do processo eletivo de magistrados para tribunais superiores da Bolívia. Revista Eletrônica Direito e Política, Programa de Pós-Graduação Stricto Sensu em Ciência Jurídica da UNIVALI, Itajaí, v.14, n.2, ${ }^{\circ}$ quadrimestre de 2019. Disponível em: www.univali.br/direitoepolitica - ISSN 1980-7791

nomes que poderão concorrer ao cargo de magistrado. Esta indicação funciona como "filtro político" deste processo eleitoral, de modo que a pré-escolha de magistrados ainda continua nas mãos do Estado da mesma forma como ocorria no sistema anterior no qual a eleição dependia de um único poder de Estado ${ }^{48}$. Nesse sentido, a vontade de projeção da independência judicial se vê questionada. Um estudo realizado pela Due Processo of Law Foundation ${ }^{49}$, no qual se produz um balanço das duas eleições (2011 e 2017) concluiu que o mecanismo das eleições nos moldes normativos realizados em ambas as eleições tem mostrado debilidade para assegurar a finalidade que se pretendeu: assegurar a composição da judicatura e a gestão da justiça de forma independente.

De acordo com o referido estudo, em ambos os processos eleitorais não se logrou atenuar a decisiva intervenção do poder político na seleção de magistrados. Esta intervenção se deu, como demonstra o estudo, pela intervenção do partido político da situação para que decidisse quem poderia ocupar cargos nas cúpulas judiciais ${ }^{50}$. Ressalta-se que o contexto de realização das eleições foi marcado por crises políticas, que confluíram para a organização da oposição política ao governo boliviano a lançar e apoiar uma campanha pelo voto nulo e branco, além de um boicote explícito de diversos advogados que, em tese, estariam aptos a candidatarem-se aos cargos. Este movimento resultou numa eleição com 14,93\% votos brancos e 50,9\% votos nulos, o que pode representar uma queda de legitimidade das eleições judiciais no país51. Como aponta Miguel Centellas, "what judicial elections have largely done [...] is reduce confidence in the competence and quality of justice system itself"52. O estudo da Due Processo of Law Foundation ainda aponta que o panorama da justiça boliviana pouco mudou com a inserção dos mecanismos eletivos de magistrados, ao passo que atualmente se questiona,

48 TERÁN, Óscar Antonio Millán. El sistema electoral para la elección de los magistrados del Tribunal Constitucional Plurinacional. Revista Ciéncia y Cultura, n. 35, Diciembre 2015.

49 FUNDACIÓN PARA EL DEBIDO PROCESO. Elecciones judiciales en Bolívia: aprendimos la lección? Massachusets : Due Process of Law Foundation, 2017, p. 22.

50 FUNDACIÓN PARA EL DEBIDO PROCESO. Elecciones judiciales en Bolívia, p. 22. Nas eleições de 2017 , os dados demonstram que $76,04 \%$ dos candidatos eram ligados ao MAS.

51 FUNDACIÓN PARA EL DEBIDO PROCESO. Elecciones judiciales en Bolívia, p. 21.

52 CENTELLAS, Miguel. Bolívia in 2017: headed into incertanties, Revista de Ciencia Politica, vol 38, n. 2, 2018, p. 171. 
BURCKHART, Thiago. Constitucionalismo e Democracia: uma análise crítica do processo eletivo de magistrados para tribunais superiores da Bolívia. Revista Eletrônica Direito e Política, Programa de Pós-Graduação Stricto Sensu em Ciência Jurídica da UNIVALI, Itajaí, v.14, n.2, 20 quadrimestre de 2019. Disponível em: www.univali.br/direitoepolitica - ISSN 1980-7791

tanto na oposição política quanto em parte da situação, se deve-se manter ou não a previsão constitucional deste instrumento ${ }^{53}$.

O segundo aspecto fundamental que fundamenta e legitima a eleição de magistrados diz respeito à intensificação da dinâmica de representatividade na sua dimensão descritiva - indenitária -, conforme define Hannah Pitkin ${ }^{54}$. Este tipo de representação atrela-se à ideia de que as instituições devem imprimir da forma mais idônea, a composição da sociedade plural. Assume relevância, nesta dinâmica, os traços identitários como a raça, religião, gênero, nacionalidade, etnia ou origem. Como aponta Jane Reis, existe um liame entre esse conceito de representação e a legitimidade de um poder como o Judiciário. Isso porque é desejável que, em democracias plurais, os órgãos do Estado, não somente o Judiciário, reflitam em caráter simbólico os multifacetados segmentos da sociedade ${ }^{55}$. Contudo, é difícil e precário de defender teoricamente que a representação do Judiciário se estenda para outras dimensões - como aquela advogada por Robert Alexy quando fala da "representação argumentativa" do Judiciário ${ }^{56}$-, pois ao Judiciário não cabe ser porta voz de uma suposta "vontade da maioria", mas de garantira seu caráter "contramajoritário" e dos direitos fundamentais. Nesse sentido, Jane Reis aponta que a atuação do magistrado não é politicamente livre, nem sua permanência no cargo está vinculada juridicamente à vontade majoritária do povo ${ }^{57}$. A defesa e legitimação da ideia de representatividade substancial atrelada à atividade judicial pode funcionar como um alicerce e mascaramento de práticas constitucionais autoritárias - que se desenvolvem a partir de um "decisionismo" sem limites -, abrindo o caminho para o "populismo judicial".

Apesar do boicote realizado pela oposição política boliviana, as eleições judiciais propiciaram que grupos concernidos com os resultados deste pleito se engajassem

\footnotetext{
53 FUNDACIÓN PARA EL DEBIDO PROCESO. Elecciones judiciales en Bolívia, p. 21.

54 Cfe. PITKIN, Hannah Fichel. The concept of representation. Berkeley :University of California Press, 1967.

55 REIS, Jane. Representação democrática do Judiciário: reflexões preliminares sobre os riscos e dilemas de uma ideia em ascensão. Revista Juspoiesis, v. 17, 2014, p. 351.

56 Cfe. ALEXY, Robert. Balancing, constitutional review and representation. International Journal of Constitutional Law, v. 3, n. 4, 572-581, out/2005.

57 REIS, Jane. Representação democrática do Judiciário, p. 14.
} 
BURCKHART, Thiago. Constitucionalismo e Democracia: uma análise crítica do processo eletivo de magistrados para tribunais superiores da Bolívia. Revista Eletrônica Direito e Política, Programa de Pós-Graduação Stricto Sensu em Ciência Jurídica da UNIVALI, Itajaí, v.14, n.2, 20 quadrimestre de 2019. Disponível em: www.univali.br/direitoepolitica - ISSN 1980-7791

de modo independente como forma de accountability do processo. Em efeito, houve um avanço considerável dos mecanismos de vigilância social do processo eletivo na eleição de 2017 comparada com a de 2011. As organizações participaram desde o processo de pré-seleção de candidatos, no qual 37 associações da sociedade civil tornaram público o documento "Siete puntos mínimos que el reglamento de preselección debe contener para garantizar la elección de magistrados independientes", como um aporte para a breve revisão normativa que ocorreu na legislação eleitoral daquele ano. Estas 37 associações constituíram a "Iniciativa Ciudadana de Monitoreo de la Justicia", e se intitula como uma articulação de redes e plataformas da sociedade civil organizada, comprometida com a promoção dos direitos humanos e o acesso à justiça que também comprometeram esforços, conhecimentos e ações para monitorar o processo de eleição judicial ${ }^{58}$. Este pontual, porém significativo, movimento participativo demonstra que houve interesse e preocupação social para que as eleições fossem bem conduzidas.

Tomando isso em consideração, é possível pontuar que a inclusão dos mecanismos eletivos para os magistrados a partir da Constituição de 2009 propiciou o aprofundamento da experiência democrática, assim como o aprofundamento do experimento constitucional. Este processo não foi construído sem oposição política, pelo qual inscreve-se sua inerente complexidade. Pensando no âmbito de sua práxis, o aprofundamento da experiência democrática - seja por meio de reformas institucionais ou da radicalidade democrática, que pode dar sustentação a uma revolução - implica na possibilidade de um número maior de pessoas participarem da esfera pública, que passa por um consequentemente alargamento. Isto leva inexoravelmente à necessidade de escutar e compreender mais de dois pontos de vista antagônicos, o que complexifica a vida política em sociedade. Do ponto de vista da teoria democrática, pode-se dizer que o processo eletivo de magistrados é inegavelmente um ganho, embora o processo eletivo - assim como qualquer processo político - é marcado por paradoxos e idiossincrasias. Como bem apontam

58 FUNDACIÓN PARA EL DEBIDO PROCESO. Elecciones judiciales en Bolívia, p. 16-18. 
BURCKHART, Thiago. Constitucionalismo e Democracia: uma análise crítica do processo eletivo de magistrados para tribunais superiores da Bolívia. Revista Eletrônica Direito e Política, Programa de Pós-Graduação Stricto Sensu em Ciência Jurídica da UNIVALI, Itajaí, v.14, n.2, 20 quadrimestre de 2019. Disponível em: www.univali.br/direitoepolitica - ISSN 1980-7791

Boaventura de Sousa Santos e Leonardo Avritzer ${ }^{59}$, "democratizar a democracia" é um dos grandes desafios para os Estados contemporâneos que encontram-se submersos aos ditames do corrente processo de financeirização da economia. Contudo, do ponto de vista da práxis política, é evidente que há a necessidade de se repensar o "modelo" de eleição, sobretudo no que se refere à pré-seleção dos candidatos.

A eleição de magistrados como ocorre na Bolívia é um exemplo de uma tentativa de conciliação da "tensão produtiva" existente entre constitucionalismo e democracia. Mostra-se evidente, entretanto, que referida "tensão produtiva" não é de fácil dissolução, pois o processo de aprofundamento da democracia e do constitucionalismo - também pode-se entendê-lo como um processo de aprofundamento da democracia através do constitucionalismo - é marcado pelo nascimento de uma série de novas tensões, que devem ser politicamente encaradas e teoricamente analisadas como "produtivas". A aclaração dos desacordos políticos de uma sociedade é o ponto que marca a difícil relação da democracia e do constitucionalismo. O desafio "político" da democracia e do constitucionalismo contemporâneos se inscreve na necessidade de transformar os profundos desacordos políticos na simbiose da cooperação política, compreendido aqui como um caminho para a construção - ou, talvez, reconstrução - do sentido do "comum" atualmente. É este caminho que a tensão dialógica e produtiva entre constitucionalismo e democracia devem ter no horizonte.

Por fim, cabe pontuar, como bem fez Gilberto Bercovici, que diante da hodierna crise da teoria da Constituição no ocidente, marcada pela excessiva formalização ou normativização do direito constitucional, provocaram um processo de "despolitização" da Constituição. Nesse sentido, compreender os fundamentos políticos da Constituição, bem como seu dimensionamento no interior da arquitetura de práticas políticas de um país é uma forma de "repolitizar" o conteúdo normativo presente em seu texto. A novidade do processo eletivo boliviano analisado neste ensaio se dá na medida em que a teoria da Constituição

59 SANTOS, Boaventura de Sousa; AVRITZER, Leonardo. Introdução: para ampliar o cânone democrático. In. SANTOS, Boaventura de Sousa (Org.). Democratizar a democracia: os caminhos da democracia participativa. Rio de Janeiro : Civilização brasileira, 2002. 
BURCKHART, Thiago. Constitucionalismo e Democracia: uma análise crítica do processo eletivo de magistrados para tribunais superiores da Bolívia. Revista Eletrônica Direito e Política, Programa de Pós-Graduação Stricto Sensu em Ciência Jurídica da UNIVALI, Itajaí, v.14, n.2, 20 quadrimestre de 2019. Disponível em: www.univali.br/direitoepolitica - ISSN 1980-7791

passa a ser repensada a partir de uma nova teoria do Estado, além de uma reformulação da noção de democracia. Esta talvez seja a contribuição mais significativa, tanto do ponto de vista teórico quanto empírico, para o patrimônio comum do constitucionalismo democrático.

\section{CONSIDERAÇÕES FINAIS}

A necessidade de reformular e refundar alguns dos preceitos fundamentais do Estado, da democracia e da Constituição estavam dentre as preocupações do novo texto constitucional boliviano, o que diretamente implica a reformulação do Judiciário para que este poder - historicamente marcado por uma frágil legitimidade democrática - possa expandir seu grau de legitimidade política, dentro das suas possibilidades fáticas. Qualquer ação nesta direção contribui para um diálogo profícuo entre o ideal do constitucionalismo e o ideal da democracia, seja do ponto de vista positivo, enquanto uma possibilidade de repolitização do direito constitucional e formação de uma "cooperação política constitucional", seja do ponto de vista negativo, no qual se demonstra a emergência dos paradoxos e contradições que são, em certa medida, inerentes a esse processo.

Se, por um lado, as eleições judiciais para magistrados de tribunais superiores possibilitam o aprofundamento simultâneo da experiência democrática e constitucional, além de um determinado grau de engajamento e participação social inovador para a história do constitucionalismo e da democracia, por outro, ele imprime e diagnostica a polarização - ou, talvez, pulverização - das correntes político-ideológicas - e também "partidárias", em certo sentido - do país. O paradoxo - ou dilema - central deste processo está relacionado com o distanciamento entre sua proposta inicial, qual seja, a de garantir uma maior autonomia e independência ao Judiciário na figura dos tribunais superiores, com suas determinações normativas e institucionais, que relegam a nomeação dos candidatos ao crivo de um órgão estatal, assemelhando-se ao sistema anterior realizado mediante indicação política. 
BURCKHART, Thiago. Constitucionalismo e Democracia: uma análise crítica do processo eletivo de magistrados para tribunais superiores da Bolívia. Revista Eletrônica Direito e Política, Programa de Pós-Graduação Stricto Sensu em Ciência Jurídica da UNIVALI, Itajaí, v.14, n.2, ${ }^{\circ}$ quadrimestre de 2019. Disponível em: www.univali.br/direitoepolitica - ISSN 1980-7791

Entende-se, portanto, que há a necessidade de aprimoramento do processo eletivo de magistrados na Bolívia, no qual perpassa, pelo menos, pelo debate e questionamento de três questões centrais: 1) a necessidade de se repensar o "modelo" de escolha e indicação dos magistrados, sobretudo no que se refere à interferência política do Órgano Electoral Plurinacional na indicação dos membros que são considerados "aptos" a concorrer ao pleito eleitoral; 2) novas formas de controle democrático e cidadão não somente no ou durante o processo eletivo, mas também posteriormente, quando os magistrados estiverem no exercício de seus mandatos, que devem obedecer rigidamente aos ditames da lei e da própria Constituição; 3) a necessidade de construir o diálogo e a cooperação política no âmbito da política ordinária - talvez esta seja a tarefa mais difícil -, haja vista que sua influência irradia diretamente no processo eletivo de magistrados da Bolívia.

\section{REFERÊNCIA DAS FONTES CITADAS}

ACKERMAN, Bruce. The Rise of World Constitutionalism. Virginia Law Review 83, no. 4, pp. 771-797, 1997.

ACUNHA, Fernando José Gonçalves. Constitucionalismo, autoritarismo e democracia na América Latina: as recentes Constituições da Bolívia e do Equador e a persistência das tradições do constitucionalismo latino-americano. Tese de Doutoramento em Direito. Universidade de Brasília, 2017.

ALEXY, Robert. Balancing, constitutional review and representation. International Journal of Constitutional Law, v. 3, n. 4, 572-581, out/2005.

AMIRANTE, Carlo. Dalla forma stato alla forma mercato. Torino: Giappichelli, 2008.

BOBBIO, Norberto. A Era dos Direitos. Rio de Janeiro : Elsevier, 2004.

BOBBIO, Norberto. Liberalismo e democracia. São Paulo : Brasiliense, 2006.

CANOTILHO, José Joaquim Gomes. Os métodos do achamento do político. In: CANOTILHO, José Joaquim Gomes et al. Comentários à Constituição do Brasil. São Paulo : Saraiva, 2013.

CENTELLAS, Miguel. Bolívia in 2017: headed into incertanties, Revista de Ciencia Politica, vol 38, n. 2, 2018. 
BURCKHART, Thiago. Constitucionalismo e Democracia: uma análise crítica do processo eletivo de magistrados para tribunais superiores da Bolívia. Revista Eletrônica Direito e Política, Programa de Pós-Graduação Stricto Sensu em Ciência Jurídica da UNIVALI, Itajaí, v.14, n.2, $2^{\circ}$ quadrimestre de 2019. Disponível em: www.univali.br/direitoepolitica - ISSN 1980-7791

CHUEIRI, Vera Karam de. Constituição radical: uma ideia e uma prática. Revista da Faculdade de Direito da UFPR, Curitiba, n. 58, 2013.

CLAVERO, Bartolomé. Bolívia entre Constitucionalismo Colonial y Constitucionalismo Emancipatorio. Conferencia presentada em La Vicepresidencia de La Republica, 2009.

DUVAL, Fábio Amaro da Silveira. Da polifonia à seletividade no discurso indigenista da esquerda boliviana. In: DUARTE, Rita. (Org.). Janus 2014. Conjuntura internacional - O estado do Estado - Metamorfoses da violência (19142014). 1ed.Lisboa: OBSERVARE - Universidade Autónoma de Lisboa, 2014.

FAVOREU, Louis. La constitucionalización del derecho. Revista de Derecho, Volumen XIII, 2001.

FUNDACIÓN PARA EL DEBIDO PROCESO. Elecciones judiciales en Bolívia: aprendimos la lección? Massachusets : Due Process of Law Foundation, 2017.

GARGARELLA, Roberto. La sala de máquinas de la Constitución: dos siglos de constitucionalismo en América Latina (1810-2010). Buenos Aires : Katz Editores, 2014.

GARGARELLA, Roberto. Constitucionalismo vs. democracia. In: FABRA ZAMORA, Jorge Luíz; SPECTOR, Ezequiel. Enciclopedia de filosofia y teoría del derecho. Vol.III. Ciudad de México : Universidad Nacional Autonoma de México, 2015.

HABERMAS, Jürgen. Direito e democracia: entre facticidade e validade. Vol. II. Tradução de Flávio Siebeneichler. Rio de Janeiro : Tempo brasileiro, 1997.

HABERMAS, Jüergen. A constelação pós-nacional: ensaios políticos. São Paulo : Littera Mundi, 2001.

HELD, David. Modelos de democracia. Belo Horizonte : Paideia, 1987.

HIRSCHL, Ran. Towards Juristocracy: the origins and consequences of the new constitutionalism. Cambridge: Harvard University Press, 2007.

HOLMES, Stephen. El precompromiso y la paradoja de la democracia. In : ESLTER, Jon; SLAGSTAD, Rune. Constitucionalismo y democracia. México : Fondo de Cultura Económica, 1999.

KELSEN, Hans. Jurisdição Constitucional. São Paulo : Martins Fontes, 2003.

LÖSING, Norbert. La jurisdiccionalidad constitucional en Latinoamerica. Traducción de Marcela Anzola Gil. Madrid : Dykinson, 2002. 
BURCKHART, Thiago. Constitucionalismo e Democracia: uma análise crítica do processo eletivo de magistrados para tribunais superiores da Bolívia. Revista Eletrônica Direito e Política, Programa de Pós-Graduação Stricto Sensu em Ciência Jurídica da UNIVALI, Itajaí, v.14, n.2, $2^{\circ}$ quadrimestre de 2019. Disponível em: www.univali.br/direitoepolitica - ISSN 1980-7791

MELO, Milena Petters. O patrimônio comum do constitucionalismo contemporâneo e a virada biocêntrica do "novo" constitucionalismo latinoamericano. Novos Estudos Jurídicos, v. 18, p. 74-84, 2013.

MIGUEL, Luis Felipe. Democracia e representação: territórios em disputa. São Paulo: Editora Unesp, 2014.

ONIDA, Valerio. La Costituzioni ieri e oggi. Bologna : Il Mulino, 2008.

PÁSARA, Luis. Elecciones judiciales en Bolívia: una experiencia inédita. Washington, DC : Due Process of Law Foundation, 2014.

PITKIN, Hannah Fichel. The concept of representation. Berkeley :University of California Press, 1967.

QUIROGA, T. J. A. El colapso del sistema judicial, síntomas de la crisis del Estado corporativo. Nueva Cronica y Buen Gobierno, 16 abr 2014.

REIS, Jane. Representação democrática do Judiciário: reflexões preliminares sobre os riscos e dilemas de uma ideia em ascensão. Revista Juspoiesis, v. 17, p. 343359, 2014.

ROJAS, Jorge Lazarte. La caja de Pandora de la justicia: el experimento del voto universal para elegir magistrados. Santa Cruz de la Sierra : Fundación Nueva Democracia, 2017.

SANTOS, Boaventura de Sousa. La globalización del derecho: los nuevos caminos de la regulación y la emancipación. Traducción de César Rodríguez. Bogotá : Instituto Latinoamericano de Servicios Legales Alternativos, ILSA, 1998.

SANTOS, Boaventura de Sousa. Refundación del Estado en América Latina: perspectivas desde una epistemología del Sul. Lima : Red Latinoamericana de Antropología Jurídica, 2010.

SANTOS, Boaventura de Sousa; AVRITZER, Leonardo. Introdução: para ampliar o cânone democrático. In. SANTOS, Boaventura de Sousa (Org.). Democratizar a democracia: os caminhos da democracia participativa. Rio de Janeiro : Civilização brasileira, 2002.

SANTOS, Boaventura de Sousa; MENESES, Maria Paula. (Orgs.) Epistemologias do Sul. São. Paulo; Editora Cortez. 2010.

SARTORI, Giovani. A teoria da democracia revisitada: o debate Contemporâneo. São Paulo, Editora Ática, 1984.

SCHUMPETER, Joseph. Capitalismo, socialismo e democracia. Rio de Janeiro: Fundo de Cultura, 1961.

SCHMITT, Carl. O guardião da Constituição. Belo Horizonte : Del Rey, 2007. 
BURCKHART, Thiago. Constitucionalismo e Democracia: uma análise crítica do processo eletivo de magistrados para tribunais superiores da Bolívia. Revista Eletrônica Direito e Política, Programa de Pós-Graduação Stricto Sensu em Ciência Jurídica da UNIVALI, Itajaí, v.14, n.2, $2^{\circ}$ quadrimestre de 2019. Disponível em: www.univali.br/direitoepolitica - ISSN 1980-7791

SUNSTEIN, Cass. Designing democracy: what constitutions do. Cambridge : Oxford University Press, 2001.

SUNSTEIN, Cass. Introducción. In : ESLTER, Jon; SLAGSTAD, Rune. Constitucionalismo y democracia. México : Fondo de Cultura Económica, 1999.

TAPIA, Luis. Una reflexión sobre la idea de Estado plurinacional. Revista OSAL (Buenos Aires: CLACSO) Año VIII, No 22, 2007.

TERÁN, Óscar Antonio Millán. El sistema electoral para la elección de los magistrados del Tribunal Constitucional Plurinacional. Revista Ciéncia y Cultura, n. 35, Diciembre 2015.

TUSHNET, Mark. The inevitable internationalization of constitutional law. Virginia Journal of International Law, vol. 49:4, 2009.

VARGAS LIMA, A. E. La evolución de la justicia constitucional en Bolivia. Apuntes sobre el modelo de control concentrado y plural de constitucionalidad. Anuario Iberoamericano de Justicia Constitucional, 20, 2016.

ZAGREBELSKY, Gustavo. Imparare democrazia. Torino :Einaudi, 2007.

ZOLO, Danilo. Prefazione. In: ZOLO, Danilo. La cittadinanza: appartenenza, identità, diritti. Roma : Laterza, 1994.

RECEBIDO EM: 13/05/2019

APROVADO EM: 19/07/2019 